\title{
JBIR-83 and JBIR-84, new promothiocin derivatives, isolated from Streptomyces sp. RI19
}

\author{
Motoki Takagi ${ }^{1}$, Keiichiro Motohashi ${ }^{1}$, Aya Nagai ${ }^{1}$, Junko Hashimoto ${ }^{1}$ and Kazuo Shin-ya ${ }^{2}$ \\ The Journal of Antibiotics (2010) 63, 405-408; doi:10.1038/ja.2010.66; published online 16 June 2010
}

Keywords: free radical scavenger; membrane filter method; promothiocin; Streptomyces

Members of the class Actinobacteria are known to produce pharmaceutically useful compounds and have been extensively studied. Soil has thus far been the primary source of Actinobacteria. However, the rate of novel compound discovery from these terrestrial strains has significantly decreased recently. Therefore, we wanted to explore the possibility of isolating unusual Actinobacteria capable of producing new metabolites by using clearly devised methods instead of general selection methods using antibiotics. For this purpose, we isolated Actinobacteria from soil samples using the membrane filter (MF) method, ${ }^{1,2}$ which allows for selection of Actinobacteria without using antibiotics. In fact, we have already reported the isolation of a new species of Streptomyces by the MF method. ${ }^{2}$ Our attempts to discover novel compounds from these actinobacterial origin resulted in the successful isolation of new promothiocin derivatives designated as JBIR-83 (1) and JBIR-84 (2) from the culture broth of Streptomyces sp. RI19 (Figure 1a). In this paper, we report the fermentation procedure to obtain $\mathbf{1}$ and $\mathbf{2}$ and their subsequent isolation, structure elucidation and in brief, their biological activities.

Strain RI19 was isolated by the MF method from a soil sample collected at Shuri, Okinawa Prefecture, Japan. The detailed method of strain isolation has been already reported. ${ }^{2}$ To identify which genus strain RI19 belongs to, we compared its 16S rRNA gene sequences with those available in the DNA Data Bank of Japan using the basic local alignment search tool. ${ }^{3}$ The strain was identified as the genus Streptomyces because its $16 \mathrm{~S}$ rRNA gene sequence exhibited a high sequence similarity of $99 \%$ with Streptomyces setonensis.

The strain was cultivated in $50 \mathrm{ml}$ test tubes, each containing $15 \mathrm{ml}$ of a seed medium consisting of starch (Kosokagaku, Tokyo, Japan) $1.0 \%$, polypeptone (Nihon Pharmaceutical, Tokyo, Japan) 1.0\%, molasses (Dai-Nippon Meiji Sugar, Tokyo, Japan) $1.0 \%$ and meat extract 1.0\% (Extract Ehlrich; Wako Pure Chemical Industry, Osaka, Japan), pH 7.2 (adjusted before sterilization). The test tubes were agitated on a reciprocal shaker ( 355 r.p.m.) at $27^{\circ} \mathrm{C}$ for 2 days.
Aliquots $(2.5 \mathrm{ml})$ of the broth were transferred to $500 \mathrm{ml}$ baffled Erlenmeyer flasks containing $100 \mathrm{ml}$ of a production medium consisting of $\beta$-cyclodextrin (Kanto Chemical, Tokyo, Japan) $4.0 \%$, glycerin $0.5 \%$, pharmamedia (Traders Protein, Lubbock, TX, USA) $2.0 \%, \mathrm{CuSO}_{4} 5 \mathrm{mg}, \mathrm{MnCl}_{2} 5 \mathrm{mg}$ and $\mathrm{ZnSO}_{4} 5 \mathrm{mg}$ (pH 7.2; adjusted before sterilization) and cultured on a rotary shaker (180 r.p.m.) at $27^{\circ} \mathrm{C}$ for 5 days.

The mycelial cake in the fermentation broth (2l) was separated from the supernatant by centrifugation followed by extraction with acetone. The extract was evaporated in vacuo to remove the acetone, and the aqueous residue was extracted with EtOAc. The organic layer was dried over $\mathrm{Na}_{2} \mathrm{SO}_{4}$ and then evaporated to dryness. The residue $(0.74 \mathrm{~g})$ was subjected to normal-phase medium-pressure liquid chromatography (Purif-Pack SI-60; Moritex, Tokyo, Japan) and developed with a gradient system of $n$-hexane-EtOAc (0-30\% EtOAc) followed by $\mathrm{CHCl}_{3}-\mathrm{MeOH}(0-50 \% \mathrm{MeOH})$. The $3 \% \mathrm{MeOH}$-eluted fraction $(60.9 \mathrm{mg})$ was further purified by preparative reversed-phase HPLC using a Pegasil ODS column $(20$ i.d. $\times 150 \mathrm{~mm}$; Senshu Chemical, Tokyo, Japan) with $65 \% \mathrm{MeOH}-\mathrm{H}_{2} \mathrm{O}$ containing $0.1 \%$ formic acid (flow rate: $10 \mathrm{ml} \mathrm{min}^{-1}$ ) to yield $1(1.75 \mathrm{mg}$; retention time, $8.74 \mathrm{~min}$ ) and 2 (3.02 $\mathrm{mg}$; retention time, $23.7 \mathrm{~min}$ ).

Compounds 1 and 2 were obtained as colorless oils $\left([\alpha]_{D}^{25}+15.0\right.$ (c 0.02 ) for 1 and +38.6 ( $c 0.14$ ) for 2 , in $\mathrm{MeOH}$ ). The molecular formulas of $\mathbf{1}$ and $\mathbf{2}$ were determined by HR-electrospray ionizationMS to be $\mathrm{C}_{34} \mathrm{H}_{36} \mathrm{~N}_{10} \mathrm{O}_{7} \mathrm{~S}_{2}$ (found: $761.2272(\mathrm{M}+\mathrm{H})^{+}$, calcd: 761.2288) and $\mathrm{C}_{37} \mathrm{H}_{39} \mathrm{~N}_{11} \mathrm{O}_{8} \mathrm{~S}_{2}$ (found: $830.2524(\mathrm{M}+\mathrm{H})^{+}$, calcd: 830.2503), respectively. In addition, 1 and 2 showed the same IR absorption $\left(v_{\max }(\mathrm{KBr}) 3400,1660 \mathrm{~cm}^{-1}\right)$, which indicated the presence of an amide functional group. UV absorptions were also identical between 1 and $2\left(1: \lambda_{\max }(\varepsilon), 313 \mathrm{~nm}\right.$ (sh, 9400) and $226 \mathrm{~nm}$ (sh, 36000$) ; 2: \lambda_{\max }$

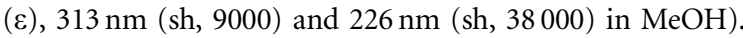

The structures of $\mathbf{1}$ and $\mathbf{2}$ were mainly determined by NMR spectral analyses and the tabulated ${ }^{13} \mathrm{C}$ and ${ }^{1} \mathrm{H}$ NMR spectral data for $\mathbf{1}$ and 2,

${ }^{1}$ Biomedicinal Information Research Center, Japan Biological Informatics Consortium, Tokyo, Japan and ${ }^{2}$ Biomedicinal Information Research Center, National Institute of Advanced Industrial Science and Technology, Tokyo, Japan

Correspondence: Dr K Shin-ya, Biomedicinal Information Research Center, National Institute of Advanced Industrial Science and Technology, 2-4-7 Aomi, Koto-ku, Tokyo 135-0064, Japan.

E-mail: k-shinya@aist.go.jp or Dr M Takagi, Biomedicinal Information Research Center, Japan Biological Informatics Consortium, 2-4-7 Aomi, Koto-ku, Tokyo 135-0064, Japan. E-mail: motoki-takagi@aist.go.jp

Received 7 April 2010; revised 13 May 2010; accepted 25 May 2010; published online 16 June 2010 


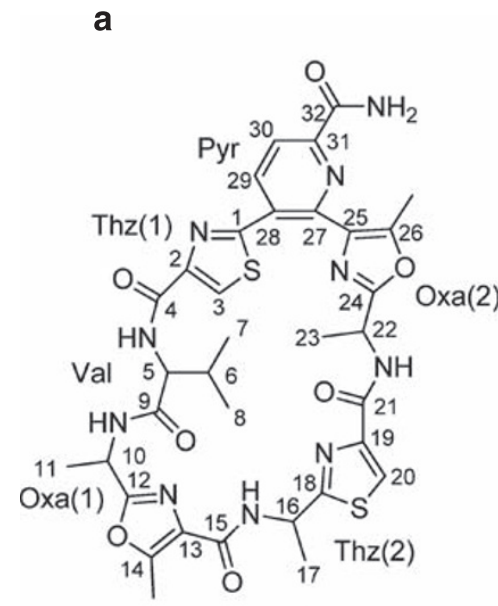

JBIR-83 (1)

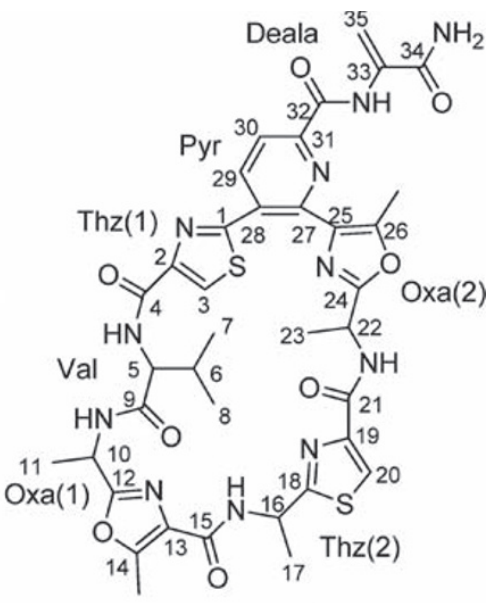

JBIR-84 (2)<smiles>C=C(NC(=O)c1ccc(-c2nc(C(=O)NC(C(=O)NCc3nc(C(=O)NC(C)c4nc(C(=O)NC(C)C(N)=O)cs4)c(C)o3)C(C)C)cs2)c(-c2nc(C(C)NC(=O)C(N)=O)oc2C)n1)C(C)C</smiles>

Promothiocin A

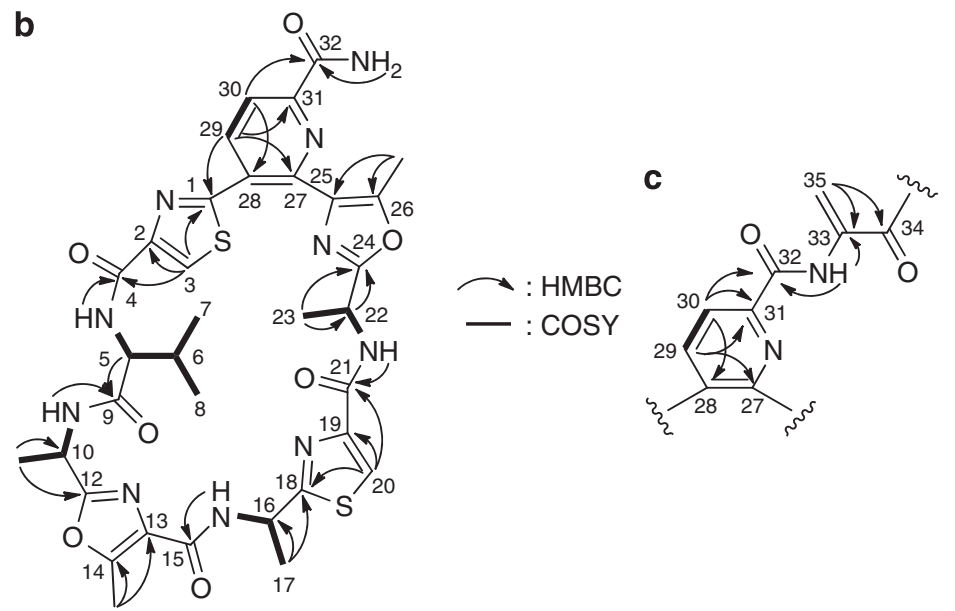

Figure 1 (a) Structures of JBIR-83 (1), JBIR-84 (2) and promothiocin A. Key correlations in double quantum filtered COSY (bold lines) and HMBC (arrows) spectra of 1 (b) and 2 (c).

which were obtained by analyses of heteronuclear single quantum coherence spectra, are shown in Table 1. Comparison of the ${ }^{13} \mathrm{C}$ and ${ }^{1} \mathrm{H}$ NMR data of 1 with those of promothiocin $\mathrm{A}^{4}$ together with $2 \mathrm{D}$ NMR spectral analyses, such as ${ }^{1} \mathrm{H}_{-}{ }^{1} \mathrm{H}$ double quantum filtered (DQF)-COSY and heteronuclear multiple bond correlation (HMBC) spectra (key correlations are summarized in Figure $1 \mathrm{~b}$ ) revealed that 1 has a similar skeleton as that of promothiocin A. In the ${ }^{1} \mathrm{H}$ NMR spectrum of 1, proton signals corresponding to amino-acid-derived partial structures, 2 thiazoles, 2 methyloxazols and a valine residue, were observed. The most characteristic difference in the ${ }^{1} \mathrm{H}$ NMR spectra between $\mathbf{1}$ and promothiocin $\mathrm{A}$ was the presence of a dehydroalanine unit. The other difference was the appearance of a 
Table $1{ }^{1} \mathrm{H}$ and ${ }^{13} \mathrm{C}$ NMR spectral data for JBIR-84 (1) and JBIR-84 (2)

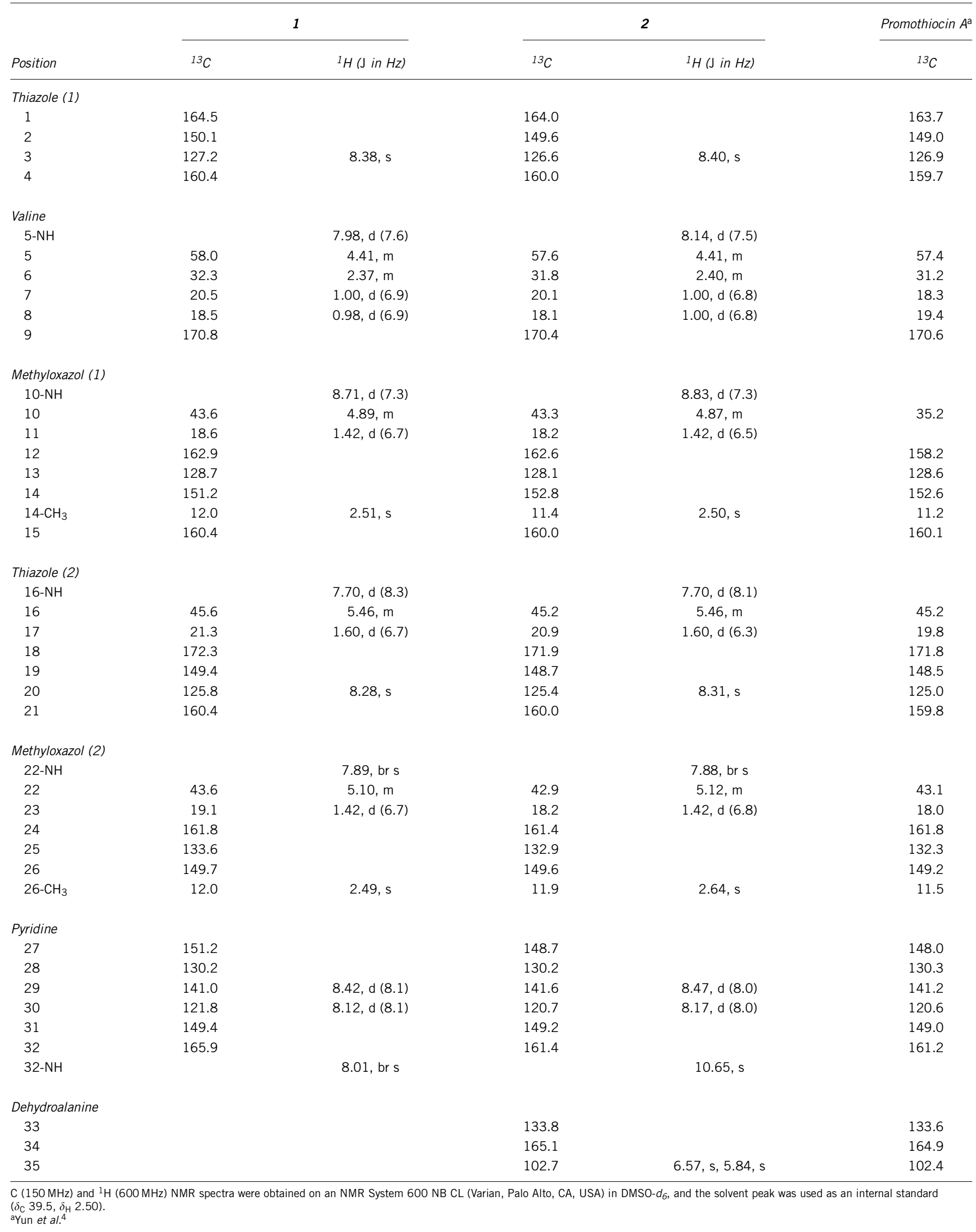


methyl proton signal at $\mathrm{H}-11\left(\delta_{\mathrm{H}} 1.42\right)$, which indicated that a glycine-originated residue was replaced by alanine in 1 . The sequence from an amide proton $10-\mathrm{NH}\left(\delta_{\mathrm{H}} 8.71\right)$ to $\mathrm{H}-11$ through methine proton $\mathrm{H}-10\left(\delta_{\mathrm{H}} 4.89\right)$ in the DQF-COSY spectrum together with the ${ }^{1} \mathrm{H}-{ }^{13} \mathrm{C}$ long-range couplings from $\mathrm{H}-11$ to $\mathrm{C}-10\left(\delta_{\mathrm{C}} 43.6\right)$ and $\mathrm{C}-12$ $\left(\delta_{\mathrm{C}} 162.9\right)$ confirmed the connectivity of the methyl group. Furthermore, the connectivities of all partial structures were confirmed by HMBC experiments as shown in Figure 1b. From these observations, the structure of 1 was established as shown in Figure 1a. It is a methyl derivative of the antibiotic 10381T. ${ }^{5}$

The ${ }^{1} \mathrm{H}$ and ${ }^{13} \mathrm{C}$ NMR signals of 2 resemble those of promothiocin A. The only difference between 2 and promothiocin A was the presence of a methyl doublet at C-11 $\left(\delta_{\mathrm{H}} 1.42, \delta_{\mathrm{C}} 18.2\right)$, which was also recognized in $\mathbf{1}$. Thus, these results show that $\mathbf{2}$ is a methyl derivative of promothiocin A at C-10 as shown in Figure 1a.

We evaluated the biological activities, namely, the cytotoxic, antimicrobial and free radical scavenging activities of $\mathbf{1}$ and 2 . The results showed that $\mathbf{1}$ protected neuronal hybridoma N18-RE-105 cells from L-glutamate toxicity, which provides an assessment of their free radical scavenging activity, ${ }^{6-8}$ with $\mathrm{EC}_{50}$ values of $74 \mu \mathrm{M}$, whereas 2 hardly showed the protective activity. The protective effect of $\mathbf{1}$ was weaker than the representative antioxidant, $\alpha$-tocopherol $\left(\mathrm{EC}_{50}=6.3 \mu \mathrm{M}\right)$. Although compounds such as phenazostatins, ${ }^{6}$ benzostatins, ${ }^{9}$ aestivophoenins ${ }^{10}$ and carbazomadurins ${ }^{11}$ isolated from actinomycete have been previously reported to show protective activity against L-glutamate toxicity, their structures are not similar to that of 1 . In addition, because radical scavenging activity could not be predicted from the chemical structures of 1 , it would be interesting to clarify the mode of action of $\mathbf{1}$. Moreover $\mathbf{1}$ and $\mathbf{2}$ did not exhibit cytotoxic activity against several cancer cell lines nor did they show antibacterial activities against Micrococcus luteus, Escherichia coli and Candida albicans.

In conclusion, we obtained new promothiocin derivatives, namely, JBIR-83 and JBIR-84, from the culture broth of Streptomyces strain
RI18 isolated using the MF method. We believe that this study will convince chemists that Actinobacteria isolated by the MF method can produce new bioactive compounds and also encourage them to investigate the isolation of Actinobacteria through a new method.

\section{ACKNOWLEDGEMENTS}

This work was supported by a grant from the New Energy and Industrial Technology Department Organization (NEDO) of Japan.

1 Hirsch, C. F. \& Christensen, D. L. Novel method for selective isolation of actinomycetes. Appl. Environ. Microbiol. 46, 925-929 (1983).

2 Nagai, A., Khan, S. T., Tamura, T., Takagi, M. \& Shin-ya, K. Streptomyces aomiensis sp. nov., a novel species of Streptomyces isolated from a soil sample using the membrane filter method. Int. J. Syst. Evol. Microbiol. (e-pub ahead of print 21 May 2010; doi:10.1099/ijs.0.020719-0).

3 Altschul, S. F., Gish, W., Miller, W., Myers, E. W. \& Lipman, D. J. Basic local alignment search tool. J. Mol. Biol. 215, 403-410 (1990).

4 Yun, B. S., Hidaka, T., Furihata, K. \& Seto, H. Promothiocins A and B, novel thiopeptides with a tipA promoter inducing activity produced by Streptomyces sp. SF2741. J. Antibiot. 47, 510-514 (1994).

5 Cornell, C. P, Grode, S. H \& Meyer, H. F. Antibiotics 10381V, W, Y, Z1, Z2, PRE-B and T US 5,736,510 (1998) (Pharmacia \& Upjohn Co.).

$6 \mathrm{Kim}, \mathrm{W}$. G. et al. New diphenazines with neuronal cell protecting activity, phenazostatins A and B, produced by Streptomyces sp.. J. Antibiot. 50, 715-721 (1997).

7 Shin-ya, K., Shimizu, S., Kunigami, T., Furihata, K. \& Seto, H. A new neuronal cell protecting substance, lavanduquinocin, produced by Streptomyces viridochromogenes. J. Antibiot. 48, 574-578 (1995).

8 Ueda, J., Hashimoto, J., Inaba, S., Takagi, M. \& Shin-ya, K. JBIR-59, a new sorbicillinoid, from a marine-derived fungus Penicillium citrinum Spl080624G1f01. J. Antibiot. 63, 203-205 (2010).

9 Kim, W. G., Kim, J. P., Kim, C. J., Lee, K. H. \& Yoo, I. D. Benzastatins A, B, C, and D: new free radical scavengers from Streptomyces nitrosporeus 30643. I. Taxonomy, fermentation, isolation, physico-chemical properties and biological activities. J. Antibiot. 49, 20-25 (1996).

10 Shin-ya, K. et al. Novel neuronal cell protecting substances, aestivophoenins A and B, produced by Streptomyces purpeofuscus. J. Antibiot. 48, 1378-1381 (1995).

11 Kotoda, N., Shin-ya, K., Furihata, K., Hayakawa, Y. \& Seto, H. Isolation and structure elucidation of novel neuronal cell protecting substances, carbazomadurins $A$ and $B$ produced by Actinomadura madurae. J. Antibiot. 50, 770-772 (1997). 